$$
2315 \% 1
$$

UCRL-JC-123194 Rev 3

PREPRINT

\title{
Size Effect and Detonation Front Curvature
}

\author{
P.C. Souers
}

This paper was prepared for submittal to the 1997 Topical Conference on Shock Compression of Condensed Matter Amherst, MA

July 27 - August 1, 1997

July 1997

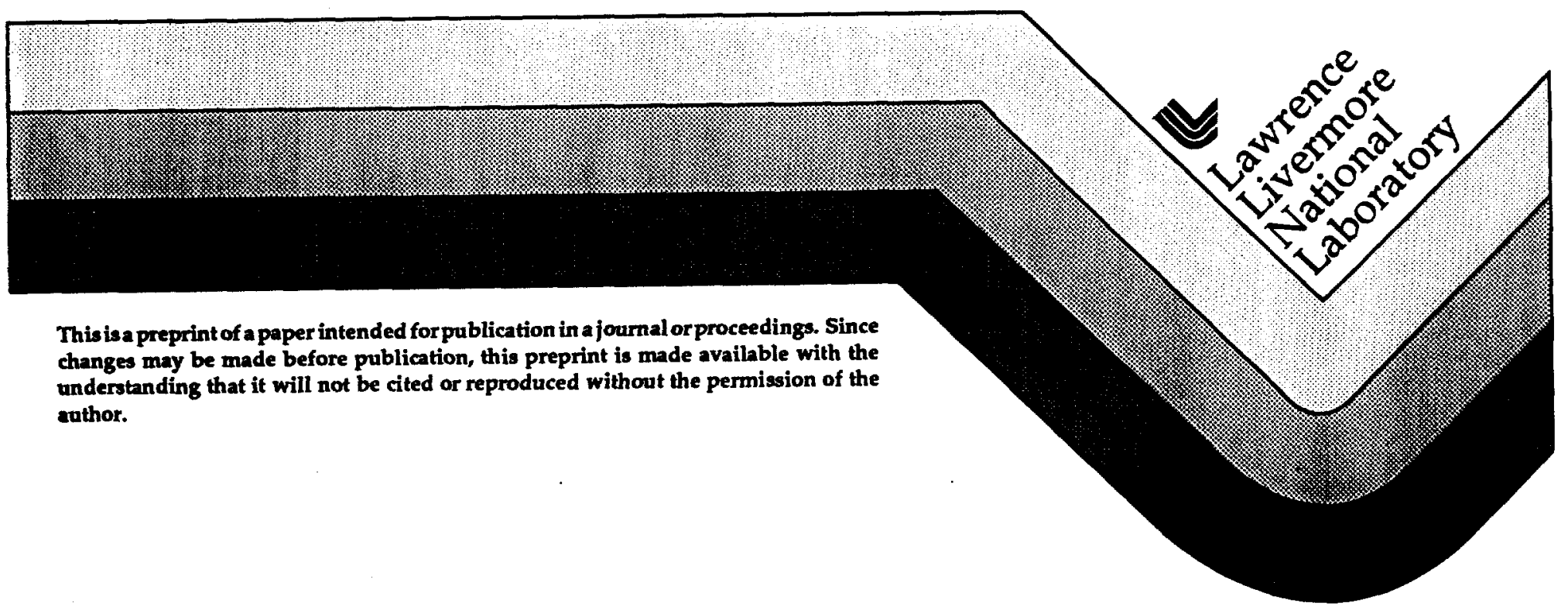




\section{P. C. Souers}

Energetic Materials Center, Lawrence Livermore National Laboratory, Livermore, California 94550 (USA)

Heat flow in a cylinder with internal heating is used as a basis for deriving a simple theory of detonation front curvature, leading to the prediction of quadratic curve shapes. A thermal conductivity of $50 \mathrm{MW} / \mathrm{mm}^{2}$ is found for TATB samples.

We first consider the size effect for CHNO explosives, where the detonation velocity declines with decreasing radius. If energy is lost out the side of the cylinder, we have:

$$
\left(\frac{<E_{o}>}{E_{o}}\right)^{1 / 2}=\frac{U_{s}}{D}=1-\frac{<x_{e}>}{\sigma R_{o}}
$$

where $E_{o}$ is the total energy of detonation, $U_{s}$ and $D$ are the detonation velocities in cylinders of radius $R_{0}$ and infinite size, and $\left\langle x_{e}\right\rangle$ is the sonic reaction zone length. Also, $\sigma$ is a wall expansion function, empirically set for unconfined samples to

$$
\sigma=11 \exp \left(-8 \frac{<x_{e}>}{R_{o}}\right)+2
$$

As the reaction zone increases, the skin layer increases exponentially to a limiting value. Eq. 2 was created empirically and is designed to enlarge the reaction zone length as the radius increases.

We now consider the detonation front, using the mathematics for uniform heat flow in a cylinder with an internal heat source. ${ }^{2}$ We replace temperature with the detonation front lag, $\mathrm{L}$, as the cause of the energy flow from the cylinder center to the edge. The thermal conductivity becomes a heat flow constant, $K$, with the units $W / \mathrm{mm}^{2}$. If $R$ is the radius, we have

$$
\frac{I}{R} \frac{\partial}{\partial R}\left(R \frac{\partial L}{\partial R}\right)=\frac{A_{o}}{K},
$$

where $A_{0}$ is the energy lost per unit volume out the side of the cylinder, because this is replaced from farther inside the cylinder. The energy must be divided by the time to cross the reaction zone $\left(<x_{e}>U_{s}\right)$ to get power. We obtain the lost energy from Eq. 1:

$$
A_{o} \approx \frac{2 U_{s} E_{o}}{\sigma R_{o}}
$$

We integrate Eq. 3 and substitute Eq. 4 to get

$$
L=\kappa R^{2}=\frac{A_{o} R^{2}}{4 K} \approx \frac{U_{s} E_{o}}{2 K \sigma R_{o}} R^{2}
$$


The lag is quadratic with radius, a result that fits fairly well for most explosives, as seen for Forbes' PBXN-111 shots in Figure $1 .^{3}$ The constant $x$ in Eq. 5 is the curvature and $1 / K$ is the radius of curvature. The quadratic relation has a $15-20 \%$ deviation at the edge. Table $1^{3-9}$ lists some of the limited data. We see that $K$ is not constant for a given group of the same explosive but increases with radius. At the cylinder edge:

$$
L_{o}=\frac{U_{s} E_{o}}{2 K \sigma} R_{o}
$$

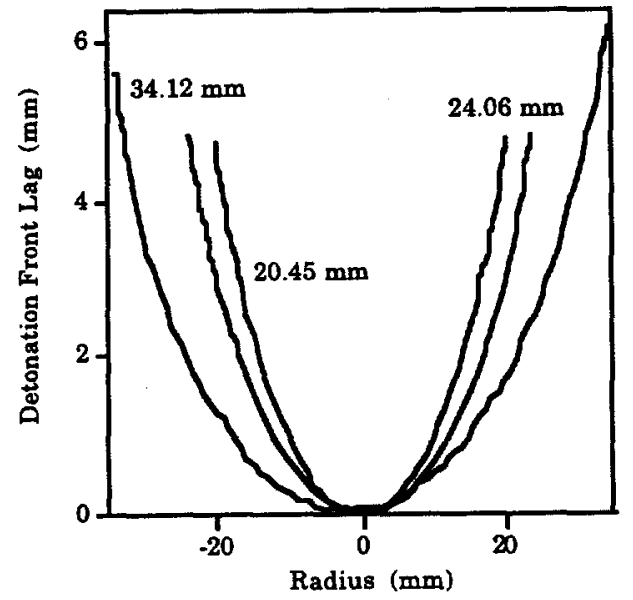

FIGURE 1. Quadratic detonation front shapes for PBXN-111 at three radii.

The thermal conductivity may be found from

$$
K=\frac{U_{s} E_{o}}{2 \kappa \sigma R_{o}}
$$

The best data in Table 1 is for the TATB explosives where $\mathrm{K} \approx 50 \mathrm{MW} / \mathrm{mm}^{2}$. We also see that

$$
<x_{e}>\approx L_{0}
$$

The explosive uses the lag to move energy to the edge but needs to keep the front as short as possible so that Eq. 8 seems reasonable in this regard. In Eq. $6, U_{s} E_{o} / K \approx 1$ and $R_{o} / 2 \sigma \approx\left\langle x_{e}\right\rangle$, so that Eq. 8 is a coincidence from our few examples.

From Eqs. 1, 5 and 8, we obtain

$$
U_{s}=D-\left(\frac{R_{o}^{2}}{\sigma}\right) \kappa
$$

This is the starting equation in Detonation Shock Dynamics and Whithams Shock Dynamics, where we see some of the structure of the constant that goes with the curvature. ${ }^{10,11}$

Table 1 and the above theory applies to most explosive data, type 1 , where voids are present to create hot spots and the reaction zone is longer than the void size. The type 2 curvature is the $1.74 \mathrm{~g} / \mathrm{cc}$ PETN curve from our laboratory shown in Figure 2.

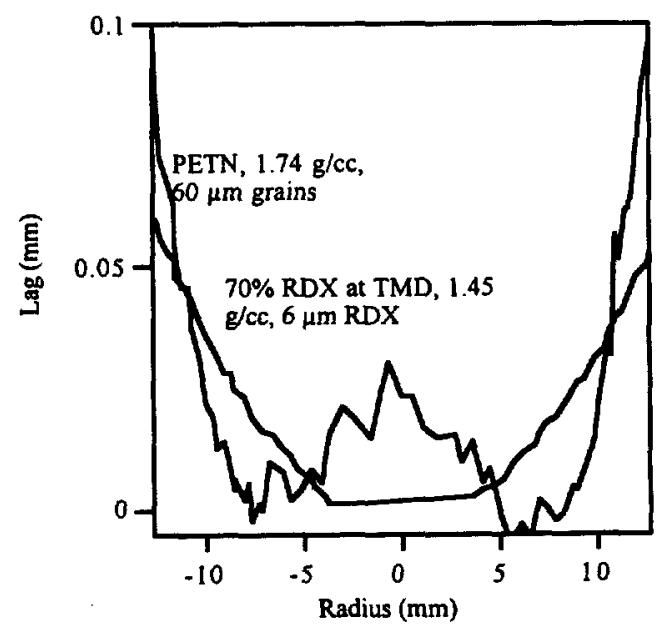

FIGURE 2. Two different types of detonation front curvatures where the edge lag is only $0.1 \mathrm{~mm}$. The PETN is not quadratic in shape: the RDX paste is quadratic but does not follow the theory in the text. 
The edge lag is only $0.1 \mathrm{~mm}$ and the curvature is rough and not quadratic. Here, we believe the intergrain voids are of the size of the reaction zone so that energy flow to the edges is scattered, producing a ragged front.

The rare type la quadratic curvature of the finegrained 70\% RDX explosive, which has had all voids pressed out that no hot spots occur, is shown in Figure $2{ }^{12,13}$ Although the edge lag is $0.1 \mathrm{~mm}$, the size effect of Eq. 6 predicts a reaction zone of 1.0 $\mathrm{mm}$. This discrepancy is caused by the added difficulty of getting the binder-enclosed grains to burn. This does not appear in pure liquids (like NM) because the liquid is continuous. The RDX shape is quadratic because the $6 \mu \mathrm{m}$ grains are smaller than the reaction zone.

\section{ACKNOWLEDGEMENTS}

We wish to thank John Bdzil, Jerry Forbes, and Damian Swift for their kind assistance in supplying curvature data from their laboratories. This work was performed under the auspices of the US Department of Energy by the Lawrence Livermore National Laboratory under contract number W-7405-ENG-48.

\section{REFERENCES}

1. P. C. Souers, "Size Effect and Detonation Front Curvature," Propellants, Explosives, Pyrotechnics, to be published.

2. H. S. Carslaw and J. C. Jaeger, Conduction of Heat in Solids, 2nd ed. (Clarendon Press, Oxford, 1959), pp. 130-132, 191, 232.

3. J. W. Forbes, E. R. Lemar, G. T. Sutherland and R. N. Baker, Detonation Wave Curvature, Corner Turning and Unreacted Hugoniot of PBXN-111, Naval Surface Warfare Center Report NSWCDD/TR-92/164, Silver Spring, MD, 1992.

4. LLNL Cylinder Test.
5. Los Alamos National Laboratory, Los Alamos, NM, unpublished data, courtesy John Bdzil, private communication, 1996.

6. D. Swift, AWE, Aldermaston, Reading, Great Britain, private communication, 1996.

7. F. Chaisse' and J. N. Oeconomos, "The Shape Analysis of a Steady Detonation Front in Right Circular Cylinders of High Density Explosive. Some Theoretical and Numerical Aspects," Proceedings Tenth Symposium (International) on Detonation, Boston, MA, July 12-16, 1993, pp. 50-57.

8. J. B. Bdzil, J. Fluid Mech. 108, 195-226 (1981).

9. R. Engleke and J. B. Bdzil, Phys. Fluids 26, 1210 (1983).

10. D. S. Stewart and J. D. Bdzil, "Examples of Detonation Shock Dynamics for Detonation Wave Spread Applications," Proceedings Ninth Symposium (International) on Detonation, Portland, OR, August 28-September 1, 1989, pp. 773-783.

11. B. D. Lambourn and D. C. Swith, "Applications of Whitham's Shock Dynamics Theory to the Propagation of Divergent Detonation Waves," ref. 10, pp. 784-797.

12. H. Moulard, J. W. Kury and A. Delclos, "The Effect of RDX Particle Size on the Shock Sensitivity of Cast PBX Formulations," Proceedings Eighth Symposium (International) on Detonation, Albuquerque, NM, July 15-19, 1985, pp. 902-913.

13. H. Moulard, "Particular Aspect of the Explosive Particle Size Effect on Shock Sensitivity of Cast PBX Formulations," ref. 10, pp. 18-24. 
TABLE 1. Summary of detonation front curvature and size effect data for various explosives in cylinders. "U" means unconfined; " $C$ " is metal-confined.

\begin{tabular}{|c|c|c|c|c|c|c|c|c|c|c|}
\hline Explosive & $\begin{array}{c}\rho_{0} \\
(\mathrm{~g} / \mathrm{cc})\end{array}$ & $\begin{array}{c}\mathbf{R}_{\mathbf{o}} \\
(\mathrm{mm})\end{array}$ & $\begin{array}{c}\mathbf{L}_{\mathbf{c}} \\
(\mathrm{mm})\end{array}$ & $\begin{array}{l}\left\langle\mathbf{x}_{\mathrm{e}}\right\rangle \\
(\mathrm{mm})\end{array}$ & $\begin{array}{c}\mathbf{K} \\
\left(\mathrm{mm}^{-1}\right)\end{array}$ & $\begin{array}{c}\mathbf{U}_{\mathrm{s}} \\
(\mathrm{mm} / \\
\mu \mathrm{s})\end{array}$ & $\begin{array}{c}\mathbf{D} \\
(\mathrm{mm} / \\
\mu \mathrm{s})\end{array}$ & $\begin{array}{c}\mathbf{K} \\
(\mathrm{MW} / \\
\left.\mathrm{mm}^{2}\right)\end{array}$ & & ref \\
\hline PBX-9502 & 1.89 & 4.99 & 0.77 & 0.9 & 0.02400 & 7.46 & 7.78 & 54 & $\mathrm{U}$ & 5 \\
\hline EDC-35 & 1.90 & 5.00 & & 0.9 & 0.02830 & 7.44 & 7.73 & 45 & $\mathrm{U}$ & 6 \\
\hline EDC-35 & 1.90 & 5.00 & & 0.9 & 0.02880 & 7.44 & 7.73 & 45 & $\mathrm{U}$ & 6 \\
\hline EDC-35 & 1.90 & 5.00 & & 0.9 & 0.03070 & 7.44 & 7.73 & 42 & $\mathrm{U}$ & 6 \\
\hline PBX-9502 & 1.89 & 5.00 & 0.74 & 0.9 & 0.02370 & 7.46 & 7.78 & 54 & $\mathrm{U}$ & 5 \\
\hline PBX-9502 & 1.89 & 6.00 & 0.78 & 1.0 & 0.01705 & 7.50 & 7.78 & 60 & U & 5 \\
\hline PBX-9502 & 1.89 & 8.98 & 1.03 & 1.4 & 0.00995 & 7.55 & 7.78 & 66 & U & 5 \\
\hline PBX-9502 & 1.89 & 24.99 & 2.18 & 2.5 & 0.00276 & 7.67 & 7.78 & 64 & U & 5 \\
\hline $\mathrm{T} 2$ & 1.86 & 25.00 & 1.92 & 2.5 & 0.00271 & 7.62 & 7.65 & 65 & $\mathrm{U}$ & 7 \\
\hline PBX-9502 & 1.89 & 25.01 & 2.08 & 2.5 & 0.00283 & 7.68 & 7.78 & 62 & $\mathrm{U}$ & 5 \\
\hline EDC-35 & 1.90 & 25.40 & & 2.5 & 0.00261 & 7.67 & 7.73 & 66 & $\mathrm{U}$ & 6 \\
\hline EDC-35 & 1.90 & 25.40 & & 2.5 & 0.00267 & 7.67 & 7.73 & 64 & $U$ & 6 \\
\hline EDC-35 & 1.90 & 25.40 & & 2.5 & 0.00284 & 7.67 & 7.73 & 60 & U & 6 \\
\hline LX-17 & 1.91 & 25.40 & 2.07 & 3.1 & 0.00293 & 7.63 & 7.72 & 39 & $\mathrm{C}$ & 4 \\
\hline $\mathrm{T} 2$ & 1.86 & 50.00 & 2.92 & 3.0 & 0.00107 & 7.63 & 7.65 & 65 & $\mathrm{U}$ & 7 \\
\hline$\overline{N M}$ & 1.12 & 6.35 & 0.21 & 0.3 & 0.00490 & 6.20 & 6.21 & 33 & $\mathrm{C}$ & 8 \\
\hline $\mathrm{NM}$ & 1.12 & 9.57 & 0.86 & 0.3 & 0.00800 & 6.21 & 6.24 & 22 & $\mathrm{U}$ & 9 \\
\hline $\mathrm{NM}$ & 1.12 & 13.78 & 0.80 & 0.2 & 0.00330 & 6.23 & 6.24 & 33 & $\mathrm{U}$ & 9 \\
\hline NM & 1.12 & 18.42 & 0.85 & 0.1 & 0.00186 & 6.23 & 6.24 & 42 & $U$ & 9 \\
\hline NM-guar & 1.17 & 5.26 & 0.98 & 1.2 & 0.03350 & 5.80 & 6.55 & 24 & $\bar{U}$ & 9 \\
\hline NM-guar & 1.17 & 6.80 & 0.95 & 0.9 & 0.01810 & 6.09 & 6.55 & 23 & U & 9 \\
\hline NM-guar & 1.17 & 9.57 & 0.99 & 1.1 & 0.00866 & 6.13 & 6.55 & 32 & U & 9 \\
\hline NM-guar & 1.17 & 18.59 & 1.13 & 1.9 & 0.00215 & 6.14 & 6.55 & 62 & U & 9 \\
\hline PBXN-111 & 1.79 & 20.45 & 4.81 & 6 & 0.01120 & 5.15 & 5.81 & 7 & $\overline{\mathrm{U}}$ & 3 \\
\hline PBXN-111 & 1.79 & 20.52 & 4.29 & 6 & 0.00981 & 5.16 & 5.81 & 8 & $\mathrm{U}$ & 3 \\
\hline PBXN-111 & 1.79 & 24.01 & 4.75 & 6 & 0.00870 & 5.31 & 5.81 & 7 & $\mathrm{U}$ & 3 \\
\hline PBXN-111 & 1.79 & 24.06 & 4.87 & 6 & 0.00797 & 5.31 & 5.81 & 8 & $\mathrm{U}$ & 3 \\
\hline PBXN-111 & 1.79 & 34.12 & 5.74 & 7 & 0.00457 & 5.57 & 5.81 & 9 & $\mathrm{U}$ & 3 \\
\hline
\end{tabular}




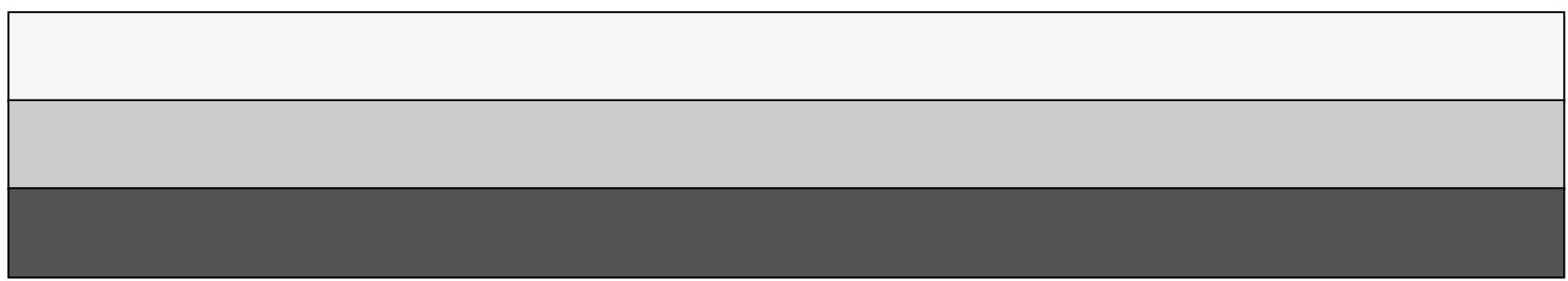

